\title{
Use of radiotherapy for bladder cancer: A population-based study of evolving referral and practice patterns
}

Xuejiao Wei ${ }^{1}$; D. Robert Siemens ${ }^{2,3}$; William J. Mackillop ${ }^{1,3,4}$; Christopher M. Booth ${ }^{1,3,4}$

${ }^{1}$ Department of Cancer Care and Epidemiology, Queen's Cancer Research Institute; ${ }^{2}$ Department of Urology, Queen's University; ${ }^{3}$ Department of Oncology, Queen’s University; ${ }^{4}$ Department of Public Health Sciences, Queen's University; Kingston, ON Canada

Funding: Dr. Booth is supported as a Canada Research Chair in Population Cancer Care.

Acknowledgements: Parts of this material are based on data and information provided by Cancer Care Ontario and CIHI. However, the analysis, conclusions, opinions, and statements expressed herein are those of the authors and not necessarily those of Cancer Care Ontario or CIHI. This study was supported by the Institute for Clinical Evaluative Sciences (ICES), which is funded by an annual grant from the Ontario Ministry of Health and LongTerm Care (MOHLTC). Parts of this material are based on data and information compiled and provided by CIHI. The opinions, results, and conclusions reported in this paper are those of the authors and are independent from the funding sources and CIHI. No endorsement by ICES or the Ontario MOHLTC is intended or should be inferred. Dr. Booth had full access to all the data in the study and takes responsibility for the integrity of the data and the accuracy of the data analysis.

Cite as: Can Urol Assoc J 2018 September 27; Epub ahead of print. http://dx.doi.org/10.5489/cuaj.5447

Published online September 27, 2018

$* * *$

\section{Abstract}

Introduction: Definitive treatment for muscle-invasive bladder cancer includes either cystectomy or radiotherapy (RT). We describe use of RT and radiation oncology (RO) referral patterns in the contemporary era.

Methods: The Ontario Cancer Registry and linked records of treatment were used to identify all patients who received cystectomy or RT for bladder cancer from 1994-2013. Physician billing records were linked to identify RO consultation before radical treatment. Multilevel logistic regression models were used to examine patient factors and physician-level variation in referral to RO and use of RT.

Results: A total of 7461 patients underwent cystectomy or RT for bladder cancer from 19942013; 5574 (75\%) had cystectomy and 1887 (25\%) had RT. Use of RT decreased from 43\% (126/289) in 1994 to 23\% (112/478) in 2008 and remained stable from 2009-2013 (23\%, 507/2202). RO referral rate among all cases decreased from 46\% (134/289) in 1994 to 30\% 
(143/478) in 2008; however, the rates began to rise in the contemporary era from 31\% (137/442) in 2009 to 37\% (165/448) in 2013 ( $\mathrm{p}=0.03)$. Patient factors associated with use of RT include older age, greater comorbidity, and geographic location. Surgeon-level factors associated with greater preoperative referral to RO include higher surgeon case volume and practicing in a teaching hospital.

Conclusions: One-quarter of patients treated with curative intent therapy for bladder cancer receive $\mathrm{RT}$. While referral rates to $\mathrm{RO}$ are increasing, future data will identify the extent to which this has altered practice. Collaborative efforts promoting multidisciplinary care and RO consultation before radical treatment are warranted.

\section{Introduction}

Primary treatment options for patients with localized muscle-invasive bladder cancer (MIBC) include cystectomy or radiotherapy (RT); long-term survival of patients have been variably reported between $45-67 \% .{ }^{1-4}$ Due to lack of contemporary level I evidence to support one modality over the other, international guidelines and practice patterns vary widely. Recent international guidelines have recommended both cystectomy and RT (with the addition of concurrent chemotherapy) as primary treatments for patients with MIBC as well as encouraging multidisciplinary care for these patients. ${ }^{5-8}$

Despite guidelines recommending multidisciplinary care, studies have shown decreasing utilization of RT in routine practice. ${ }^{4,9,10}$ We have reported practice patterns in the Canadian province of Ontario during 1994 to 2008 and showed that proportional use of RT decreased over time; 34\% of all curative intent treatment in 1994-1998, 25\% in 1999-2003, 22\% in 20042008. ${ }^{4}$ Lower utilization of RT for MIBC in the general population may be due to absolute or relative contraindications based on patient or disease variables, as well as potential processrelated factors. Under-utilization of RT may be due to low referral rate from urologists to radiation oncology ( $\mathrm{RO}$ ), low rate of $\mathrm{RT}$ recommendation from $\mathrm{RO}$, and/or patient preference. We have previously reported decreasing RO referral rates in Ontario during 1994-2008 (41\% in 1994-1998, 31\% in 1999-2003, 28\% in 2004-2008). Moreover, only $10 \%$ of patients treated with cystectomy were seen by a RO before surgery. ${ }^{11}$ There are limited data to evaluate contemporary practice patterns in light of recent data demonstrating encouraging outcomes of organ-sparing approaches and guidelines endorsing multi-disciplinary care. We undertook the following study to provide insight into referral patterns to RO and subsequent use of RT in the modern era. We also explored the extent to which physician-level (radiation oncologist, urological surgeon) variation explains differences in practice and referral patterns.

\section{Methods}

Study design and population

This is a population-based, retrospective cohort study to describe the contemporary use of RT and RO referral patterns among all patients with bladder cancer treated with curative intent 
cystectomy or RT in the Canadian province of Ontario. We have previously reported practice and referral patterns during 1994-2008. ${ }^{411}$ In this report we present updated analyses to include patients treated in 2009-2013; we also describe physician-level factors associated with practice. Ontario has a population of approximately 13.5 million people and a universal health insurance program. All incident cases of bladder cancer in Ontario with urothelial carcinoma, adenocarcinoma, and squamous cell histology treated with radical cystectomy or RT during 1994-2013 were included. The study was approved by the Research Ethics Board of Queen’s University. This study was designed, analyzed, and reported in accordance with the STROBE (Strengthening the Reporting of Observational Studies in Epidemiology) statement. ${ }^{12}$

\section{Data sources}

The Ontario Cancer Registry (OCR) is a passive, population-based cancer registry that captures diagnostic and demographic information on $\sim 98 \%$ of all incident cases of cancer in the province of Ontario. ${ }^{13}$ The OCR does not compile information about extent of disease or treatment. A variety of electronic administrative health databases were linked to the OCR. Indicators of the socioeconomic status (SES) of the community in which patients resided at diagnosis from Canadian census were linked, as described previously. ${ }^{14}$ Records of hospitalization from the Canadian Institute for Health Information Discharge Abstract Database (CIHI DAD) provided information about surgical interventions; these records are known to be consistent and complete. ${ }^{15}$ The clinical databases of Ontario's comprehensive cancer centers provided records of RT. These centres are the only providers of RT in the province and the electronic RT records are known to be $95 \%$ complete and 99\% accurate with respect to total dose, number of fractions, date of therapy, body region irradiated, and treatment intent. ${ }^{16}$ Provincial physician billing records from the Ontario Health Insurance Plan (OHIP) were used to identify RO referrals. Physician characteristics were identified from the OHIP Corporate Provider Database (CPDB). Datasets were linked using unique encoded identifiers and analyzed at the Institute for Clinical Evaluative Sciences (ICES).

\section{Definition of RT use and RO consultation}

Cases treated with radical RT were identified from the RT treatment records of the regional cancer centres (RCC). Cases treated to the bladder or pelvis with curative-intent were included as were those with missing intent who were treated with $<250 \mathrm{cGy} /$ fraction. Cases treated with surgery and RT were further classified based on the sequence and timing of both modalities: surgical case with preoperative RT (surgery $<16$ weeks after completing RT); RT case with salvage surgery (surgery $>16$ weeks after completing RT); surgical case with postoperative RT (RT starting < 16 weeks after surgery); surgical case with salvage RT (RT starting $>16$ weeks after surgery). Patients were classified as having seen a radiation oncologist in the pretreatment setting if there was a RO physician billing code within 16 weeks before surgery/radical RT. We have used a similar approach elsewhere to identify referral to medical oncology. ${ }^{17}$ Surgeons were identified using OHIP unique identifiers. 


\section{Definition of explanatory variables}

We constructed a variety of patient-level variables hypothesized to influence the referral to RO. In particular, we categorized patients by their age, sex, socioeconomic status, level of comorbidity, geographic region of residence, histology, time interval from diagnosis to radical treatment, and year of treatment. Comorbidity was classified using the Charlson Index modified for administrative data based on all non-cancer diagnoses recorded during any hospital admission within 5 years prior to surgery. ${ }^{18}$ Patient location of residence at the time of diagnosis was described at the level of 14 Local Health Integration Networks in Ontario.

Physician-level variables include physician's sex, age at date of service provided, and year of medical school graduation (as an indicator of clinical experience). For surgeons, patient volume and location of practice (teaching vs non-teaching hospital) were also identified. Surgeon volume was determined based on the mean number of annual cases over a 5-year study period, as previously reported. ${ }^{19}$ Cases were divided into quartiles by surgeon volume index.

\section{Statistical analysis}

Comparisons of proportions between study groups were made using the Chi-squared test; temporal trends were evaluated using the Cochran-Armitage test for trend. To describe the temporal trends, we classified the study population into four temporal periods based on year of radical treatment: 1994-1998, 1999-2003, 2004-2008, and 2009-2013. We fit logistic regression models to determine the independent predictors of RT use and referral to RO in the full study cohort. We then used multilevel logistic regression models to identify the patient and RO factors independently associated with RT use among patients seen by RO. We also used multilevel logistic regression models to identify the patient and surgeon factors independently associated with referral to RO among patients who underwent cystectomy.

The use of multilevel logistic regression models allowed us to account for the withinphysician correlation by incorporating random effect for physicians (i.e. RO or surgeon) into the models. In these analyses, the patient was treated as the unit of analysis but accounted for clustering of patients within physicians. Sequential building of the multilevel logistic regression models was done using a series of 3 nested models as is suggested. ${ }^{20}$ Model 1 simply included the physician identifiers as clustering variable. Model 2 adjusted for patient-level factors. Model 3 , the final adjusted model, further controlled for physician-level factors.

To explore the extent to which physician-level variation explains differences in practice, the intraclass correlation coefficient (ICC) was estimated by using the threshold method. ${ }^{21}$ The ICC represents the percent variance in patients receiving RT or seeing RO that is attributable to the radiation oncologists or surgeon, respectively. The ICC in Model 2 estimates the proportion of practice variation that is attributable to the physician after adjusting for case mix. Finally, we applied the fitted regression model (for patient factors associated with use of RT among patients referred to RO) to patients not referred to $\mathrm{RO}$ to compute their predicted probability of receiving RT had they been referred to RO. 
As per institutional policy, data that relate to $<6$ patients are not reported owing to small size. All analyses were performed using SAS version 9.4 (SAS Institute, Cary, NC).

\section{Results}

Study population

During 1994-2013, 7461 patients with bladder cancer in Ontario underwent curative-intent treatment; 5574 (75\%) had cystectomy and 1887 (25\%) underwent RT (Supplemental eFigure 1). Patients with salvage surgery $(\mathrm{N}=102)$ or peri-operative $\mathrm{RT}(\mathrm{N}=200)$ were excluded from the study population. Thirty-two percent (2416/7461) of patients were seen by RO before radical treatment. The characteristics of the study population are shown in Table 1. Most patients (84\%) were over 60 years of age and 75\% were males. Older patients and those with greater comorbidity were more likely to receive RT and to see RO before radical treatment.

RT use

The proportion of patients treated with RT for curative intent decreased from $43 \%$ in 1994 to $23 \%$ in 2008 and remained stable within the most recent study era (22\% in 2009 and $22 \%$ in 2013, $P=$ 0.867) (Figure 1).

Factors associated with use of RT are shown in Table 2. In adjusted analyses, advanced age $(P<0.001)$ and greater comorbidity $(P<0.001)$ were associated with greater RT utilization. RT rates varied three-fold across geographic regions (range 15-47\%, $P<0.001$ ). After adjusting for case mix, patients treated in the more recent era were less likely to receive RT $(P<0.001)$. Factors associated with RT use in patients treated in 2009 to 2013 were consistent with the full study period (data not shown).

\section{$R O$ referral before radical treatment}

Among the full study population, 32\% (2416/7461) were seen by RO before cystectomy/radical RT. RO referral rate decreased from 40\% (1994-1998) to 30\% (1999-2003) to 28\% (2004-2008); however, the rates began to rise in the most recent years (31\% in 2009 and 37\% in 2013 ( $P<$ 0.001) (Figure 2). A similar trend was seen in preoperative referral rate among patients who eventually underwent cystectomy (11\% in 1994-1998, 9\% in 1999-2008, and 14\% in 2009-2013) $(P=0.004)$; with significant increase in referral rates during $2009-2013$ (12\% in 2009 to $19 \%$ in 2013, $P=0.007)$.

Factors associated with RO referral before definitive therapy are shown in Table 3. In adjusted analyses, older age $(P<0.001)$ and greater comorbidity $(P<0.001)$ were associated with RO referral before radical treatment. There was substantial geographic variation in RO referral rates (range 20-52\%, $P<0.001$ ). Factors associated with RO referral before radical therapy in patients treated in 2009 to 2013 were consistent with the full study period (data not shown). 
$R T$ use and radiation oncologist-level variation in referred patients

Seventy-five percent (1813/2416) of referred patients were treated with RT. The proportion of referred patients receiving RT decreased over time (82\% in 1994-1998, 78\% in 1999-2003, 75\% in 2004-2008, 68\% in 2009-2013, $\mathrm{P}<0.001$ ) (Figure 2). Seventy-four percent of patients seen by RO were referred by an urologist, $14 \%$ of patients were referred by medical oncologist, and $12 \%$ of patients were referred by another physician (Supplemental eFigure 2).

Multilevel data in which patients were clustered within radiation oncologists were used to investigate factors associated with use of RT. We identified 148 radiation oncologists who treated patients in this study. Three percent (72/2461) of referred patients were missing radiation oncologist identifiers and were excluded from this analysis. Eighty percent of radiation oncologists were male and 39\% had graduated from medical school $>20$ years earlier. The ICC provides an estimate of the percent variance in receiving RT that is attributable to the radiation oncologist. The Model 1 ICC is estimated at 0.12 , suggesting that $12 \%$ of the variance in receiving $\mathrm{RT}$ is attributable to the $\mathrm{RO}$ before adjusting for patient and $\mathrm{RO}$ characteristics. After adjustment for patient-level characteristics in Model 2, the percent variance attributable to the RO decreased to 4\%. In Model 3, the final model, adjustments are made for both patient and RO characteristics (Table 3). Adjusting for RO had little effect on the overall variance attributable to the radiation oncologist (4\% to $3 \%$ ).

As shown in Table 3, patient characteristics associated with RT use among referred patients include older age, greater comorbidity, and geographic location. Patients referred to RO by a medical oncologist were more likely to receive RT than those referred by a urologist. After adjusting for case mix, radiation oncologists with more years in practice were significantly less likely to treat patients with RT.

Finally, applying the results of the regression analysis of those that received RT for their bladder cancer to the 5045 patients who were not referred to RO before cystectomy demonstrated an average RT probability of $60 \%$. The proportion of non-referred patients with $>50 \%$ and $>80 \%$ probability of receiving RT was $68 \%$ and $16 \%$, respectively.

Preoperative RO referral and surgeon-level variation

Multilevel data in which patients were clustered within radiation oncologists were used to investigate factors associated with use of RT. There were 313 urologists who treated the patients in this study identified. Eight percent (443/5574) of cystectomy cases were missing surgeon identifiers and therefore were excluded from this analysis. Ninety-six percent of urologists were male, $60 \%$ were $>40$ years of age, and $46 \%$ had graduated from medical school $>20$ years earlier. The Model 1 ICC for surgeon is estimated at 0.22 , indicating that $22 \%$ variance in seeing RO is attributable to the surgeon before adjusting for individual patient and surgeon characteristics. After adjustment for patient-level variables in Model 2, the percent variance attributable to the surgeon dropped to 19\%. In Model 3, (adjusting for patient and surgeon characteristics) the percent of variance in seeing RO attributable to the surgeon was $16 \%$. 
After adjusting for patient characteristics, surgeons practiced in a teaching hospital and had higher case volume were significantly more likely to have patients seen by RO (Table 4).

\section{Discussion}

We explored use of RT and referral to RO among patients with bladder cancer in the general population of Ontario during 1994-2013. Several important findings have emerged. First, the utilization rate of curative intent RT remained stable in the contemporary era; however, the proportion of patients seen by RO before definitive therapy is beginning to increase. Future data will identify the extent to which shifting referral patterns influence practice. Second, RT use and referral to RO are associated with older age and greater comorbidity. There is substantial geographical variation in treatment and referral patterns. Third, whether a referred patient underwent RT had more to do with the patient factors than any variation in practice patterns among ROs. Fourth, approximately $18 \%$ of the variability in whether a patient sees RO is attributable to the surgeon. Finally, our data suggest that RT use may be suboptimal as our modeling exercise suggests that more than half of non-referred cases may have been eligible for RT.

Despite a renewed call for multidisciplinary care and recent trials of chemoradiotherapy ${ }^{6,7,22}$, our data do not show an increase in contemporary use of RT as an organ-sparing approach to MIBC. This observation is consistent with a recent report from the United States. ${ }^{23}$ However, in the more recent era in this study we do show an increased trend in RO referral rates suggesting that practice may be starting to shift. Of the 7461 patients treated for cure in this cohort, 25\% underwent primary RT. In addition to lag/late adoption of multidisciplinary care described in recent practice guidelines, other factors that may have limited higher rates of RT utilization include key patient- and disease-related variables that would lead to relative ineligibility for $\mathrm{RT} .{ }^{24}$ However, there has been little focus on other processes of care (such as referral rates to RO and patient preferences) that may influence the uptake of organsparing approaches for MIBC. In the current study, we explored two steps in the care pathway including referral to RO and subsequent use of RT while considering provider-level variation. Only a small proportion (4\%) of variability in RT use in referred patients was attributable to RO. Our data suggest that $19 \%$ of the variability in referral rates is attributable to the referring surgeon. These findings coincide with the "gatekeeper” effect and a recent study investigating barriers and enablers to use of RT. ${ }^{25}$ Although the variability among surgeons is greater than ROs, it is notable that $\sim 81 \%$ of variation is explained by differences at the patient-level. Surgeons who had higher volume of patients and practiced in a teaching hospital were more likely to have their patients seen by a RO. A surgeon who practices in a teaching hospital may be more likely to be aware of new cancer treatment options or new practice patterns, or may be more likely to adopt new guidelines ${ }^{26,27}$; they may also have greater access to RO consultants.

We have recently shown that referral to medical oncology and use of peri-operative chemotherapy have increased substantially in recent years (from $21 \%$ in 2009 to $44 \%$ in 2013 ). ${ }^{28}$ 
In contrast with the referral and practice patterns of chemotherapy, utilization of RT for bladder cancer has remained stable and the rates of referral to RO have gradually started to increase; the reasons for this apparent lag in uptake of bladder-sparing RT are not known. Our previous work has also shown that utilization of RT for bladder cancer varies considerably across geographic regions; the reasons for this are not understood. ${ }^{11}$

Some major strengths of the current study are its large sample size and the reflection of routine clinical practice. By including a population-based sample, it is possible to minimize the referral and selection biases that plague institutional-based studies. ${ }^{29}$ To our knowledge, this is the first study to describe the process of care leading to RT and also the first to estimate the proportion of practice variation that is provider-driven.

Our study has several important limitations. Existing data sources do not include information related to clinical stage, performance status, and renal function; this limits our ability to evaluate appropriateness of case selection for RT. Our results also do not take into account patient preference or disease characteristics which could lead to appropriate non-referral by urologists or appropriate non-treatment by ROs. Furthermore, it is likely that a small proportion of cystectomy cases included in this analysis would have had non-muscle invasive disease; these would not have been eligible for RT. The focus of this study was on those patients treated with curative intent surgery and RT. The existing data sources do not allow us to identify potentially curable patients who did not receive either treatment modality; moreover, we are not able to identify potentially curable cases treated with palliative intent RT. While the health administrative databases used in this study are of good quality ${ }^{15}$, the validity of specific type of procedure or billing code has not been widely assessed. Finally, while this is an updated study the most contemporary study year is 2013; thus, the data may not reflect current practice.

\section{Conclusion}

Our study demonstrates that although use of RT for bladder cancer has remained stable the rates of referral to RO have started to increase suggesting that practice patterns may be starting to shift to more collaborative, multi-disciplinary care as described in most guidelines. Future data will identify the extent to which this has altered treatment delivery. Urologists, as the "gatekeeper" to treatment options, play a key role in uptake of RT. Future work is needed to better understand patient and physician preference in making treatment decisions. Collaborative efforts promoting multidisciplinary care are warranted. 


\section{References}

1. Madersbacher S, Hochreiter W, Burkhard F, et al. Radical cystectomy for bladder cancer today--a homogeneous series without neoadjuvant therapy. J Clin Oncol 2003;21:690-6.

2. Lin T, Fan X, Zhang C, et al. A prospective randomised controlled trial of laparoscopic vs open radical cystectomy for bladder cancer: Perioperative and oncologic outcomes with 5-year follow-up. Br J Cancer 2014;110:842-9.

3. Kitamura H, Tsukamoto $\mathrm{T}$, Shibata $\mathrm{T}$, et al. Randomised phase III study of neoadjuvant chemotherapy with methotrexate, doxorubicin, vinblastine and cisplatin followed by radical cystectomy compared with radical cystectomy alone for muscle-invasive bladder cancer: Japan clinical oncology group study JCOG0209. Ann Oncol 2014;25:1192-8.

4. Booth CM, Siemens DR, Li G, et al. Curative therapy for bladder cancer in routine clinical practice : A population-based outcomes study. Clinical Oncology 2014;26:50614.

5. Witjes JA, Compérat E, Cowan NC, et al. EAU guidelines on muscle-invasive and metastatic bladder cancer: Summary of the 2013 guidelines. Eur Urol 2014;65:778-92.

6. Milowsky MI, Rumble RB, Booth CM, et al. Guideline on muscle-invasive and metastatic bladder cancer (European Association of Urology Guideline): American Society of Clinical Oncology clinical practice guideline endorsement. J Clin Oncol 2016;34:1945-52.

7. The National Institute for Health and Care Excellence (NICE). Bladder cancer: diagnosis and management. NICE 2015.

8. National Comprehensive Cancer Network. NCCN Guidelines Bladder Cancer 2013.

9. Snyder C, Harlan L, Knopf K, et al. Patterns of care for the treatment of bladder cancer. $J$ Urol 2003;169:1697-701.

10. Gore JL, Litwin MS, Lai J, et al. Use of radical cystectomy for patients with invasive bladder cancer. J Natl Cancer Inst 2010;102:802-11.

11. Quirt JS, Siemens DR, Zaza K, et al. Patterns of referral to radiation oncology among patients with bladder cancer: A population-based study. Clin Oncol 2017.

12. Elm E von, Altman DG, Egger M, et al. Strengthening the reporting of observational studies in epidemiology (STROBE) statement: Guidelines for reporting observational studies. BMJ 2007;335:806-8.

13. Clarke EA, Marrett LD KN. Cancer registration in Ontario: A computer approach. In: Jenson OM, Parkin DM, MacLennan R, editors. Cancer registration principles and methods. Lyon, France: IARC; 1991; 246-57.

14. Booth CM, Li G, Zhang-Salomons J, et al. The impact of socioeconomic status on stage of cancer at diagnosis and survival. Cancer 2010;116:4160-7.

15. Williams JI, Young W. A summary of studies on the quality of health care administrative databases in Canada. In: Goel V, Williams JI, Anderson GM, et al, editors. Patterns of health care in Ontario: the ICES practice atlas. Ottawa: Canadian Medical Association; 1996:339-45.

16. Mackillop WJ, Fu H, Quirt CF, et al. Waiting for radiotherapy in Ontario. Int J Radiat Oncol Biol Phys 1994;30:221-8.

17. Booth CM, Siemens DR, Peng Y, et al. Patterns of referral for perioperative chemotherapy among patients with muscle-invasive bladder cancer: A population-based 
study. Urol Oncol 2014;32:1200-8.

18. Deyo RA, Cherkin DC, Ciol MA. Adapting a clinical comorbidity index for use with ICD-9-CM administraive databases. J Clin Epidemiol 1992;45.

19. Siemens DR, Mackillop WJ, Peng Y, et al. Processes of care and the impact of surgical volumes on cancer-specific survival: A population-based study in bladder cancer. Urology 2014; 84: 1049-57.

20. Gelman A, Hill J. Data analysis using regression and multilevel/hierarchical models. Cambridge university press; 2007.

21. Snijders TS, Bosker R. Multilevel analysis: An introduction to basic and advanced multilevel modeling. Thousand Oaks, Calif: Sage; 1999.

22. James ND, Hussain SA, Hall E, et al. Radiotherapy with or without chemotherapy in muscle-invasive bladder cancer. N Engl J Med 2012;366:1477-88.

23. Cahn DB, Handorf EA, Ghiraldi EM, et al. Contemporary use trends and survival outcomes in patients undergoing radical cystectomy or bladder-preservation therapy for muscle-invasive bladder cancer. Cancer 2017;123.22: 4337-45.

24. Logue J, Mcbain CA. Radiation therapy for muscle-invasive bladder cancer: Treatment planning and delivery. Clin Oncol 2005;17:508-13.

25. Walker M, French SD, Doiron RC, et al. Bladder-sparing radiotherapy for muscleinvasive bladder cancer: A survey of providers to determine barriers and enablers. Radiother Oncol 2017;125:351-6.

26. Freiman MP. The rate of adoption of new procedures among physicians: The impact of specialty and practice characteristics. Med Care 1985;23:939-45.

27. Mcfall SL, Warnecke RB, Kaluzny AD, et al. Articles practice setting and physician influences on judgments of colon cancer treatment by community physicians 1996.

28. Booth CM, Karim S, Brennan K, et al. Peri-operative chemotherapy for bladder cancer in the general population: Are practice patterns finally changing?. European Journal of Cancer 2017;72:S191.

29. Booth CM, Mackillop WJ. Translating new medical therapies into societal benefit. JAMA 2008;300:2177. 


\section{Figures and Tables}

Fig. 1. Temporal trends in incidence, cystectomy, and radical radiotherapy for bladder cancer in Ontario, 1994-2013. Note: Incident cases reflect those cases diagnosed in 1994-2013. Surgical and radiotherapy cases were treated in 1994-2013, but may have been diagnosed in earlier years.

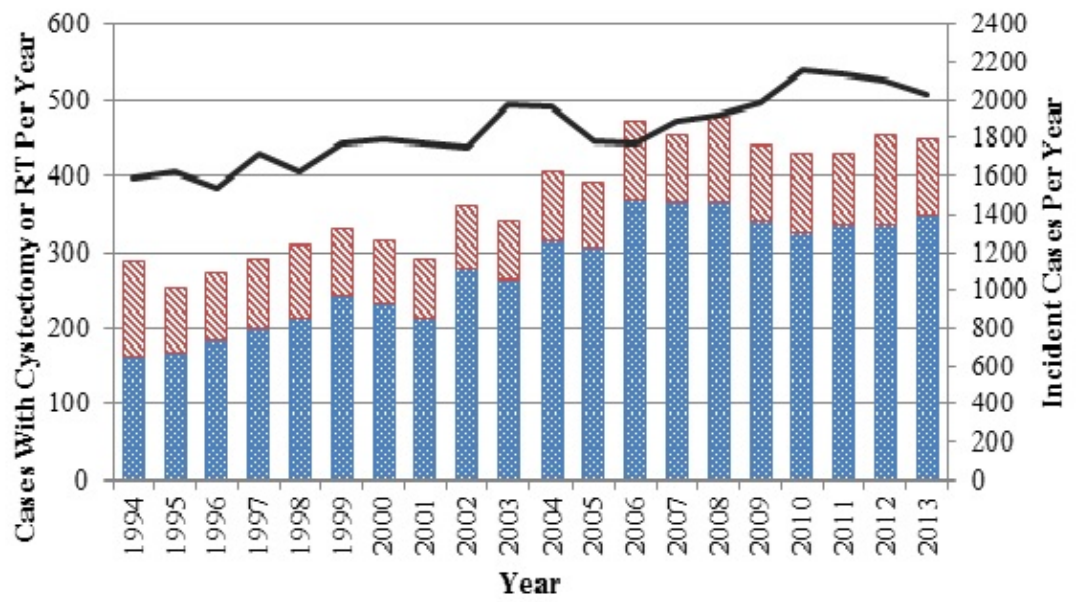

Surgical cases $\quad$ amw Radiotherapy cases Incident cases

Fig. 2. Temporal trends in referral to radiation oncology and radical radiotherapy use for patients with bladder cancer in Ontario, 1994-2013.

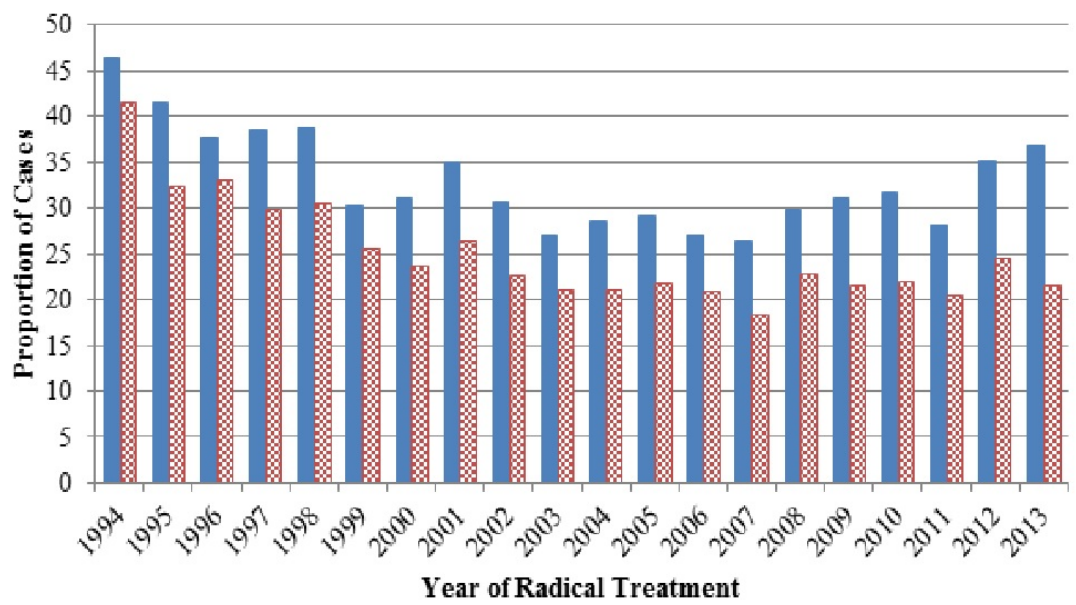

- Seen by RO before treatment $\quad$ Seen by RO and received RT 


\begin{tabular}{|c|c|c|c|c|c|}
\hline \multirow[t]{2}{*}{ Characteristics } & \multirow[b]{2}{*}{$\begin{array}{c}\text { All patients } \\
n=7461\end{array}$} & \multicolumn{2}{|c|}{ Definitive treatment } & \multicolumn{2}{|c|}{$\begin{array}{c}\text { Radiation oncology } \\
\text { referral before } \\
\text { definitive treatment }\end{array}$} \\
\hline & & $\begin{array}{c}\text { Cystectomy } \\
n=5574\end{array}$ & $\begin{array}{c}\text { Radiotherapy } \\
\mathbf{n}=\mathbf{1 8 8 7}\end{array}$ & $\begin{array}{c}\text { Yes } \\
n=2416\end{array}$ & $\begin{array}{c}\text { No } \\
n=5045\end{array}$ \\
\hline \multicolumn{6}{|l|}{ Age, years ${ }^{1}$} \\
\hline $20-49$ & $285(4 \%)$ & $255(5 \%)$ & $30(2 \%)$ & $58(2 \%)$ & $227(4 \%)$ \\
\hline $50-59$ & $892(12 \%)$ & $773(14 \%)$ & $119(6 \%)$ & $186(8 \%)$ & $706(14 \%)$ \\
\hline $60-69$ & $1885(25 \%)$ & $1600(29 \%)$ & $285(15 \%)$ & $\begin{array}{c}435 \\
(18 \%) \\
\end{array}$ & $\begin{array}{c}1450 \\
(29 \%) \\
\end{array}$ \\
\hline $70-79$ & $2843(38 \%)$ & $2175(39 \%)$ & $668(35 \%)$ & $\begin{array}{c}873 \\
(36 \%) \\
\end{array}$ & $\begin{array}{c}1970 \\
(39 \%) \\
\end{array}$ \\
\hline $80+$ & $1556(21 \%)$ & $771(14 \%)$ & $785(42 \%)$ & $\begin{array}{c}864 \\
(36 \%) \\
\end{array}$ & $692(14 \%)$ \\
\hline Sex & & & 2 & 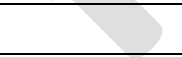 & \\
\hline Female & $1832(25 \%)$ & $1392(25 \%)$ & $440(23 \%)$ & $\begin{array}{c}583 \\
(24 \%)\end{array}$ & $\begin{array}{l}1249 \\
(25 \%)\end{array}$ \\
\hline Males & $5629(75 \%)$ & $4182(75 \%)$ & $1447(77 \%)$ & $\begin{array}{c}1833 \\
(76 \%) \\
\end{array}$ & $\begin{array}{l}3796 \\
(75 \%)\end{array}$ \\
\hline \multicolumn{6}{|c|}{ Socioeconomic status by quintile ${ }^{2}$} \\
\hline 1 & 1452 (19\%) & 1065 (19\%) & 387 (21\%) & $\begin{array}{c}468 \\
(19 \%)\end{array}$ & $984(20 \%)$ \\
\hline 2 & $1536(21 \%)$ & $1161(21 \%)$ & $375(20 \%)$ & $\begin{array}{c}480 \\
(20 \%) \\
\end{array}$ & $\begin{array}{l}1056 \\
(21 \%)\end{array}$ \\
\hline 3 & $1531(21 \%)$ & $1134(20 \%)$ & $397(21 \%)$ & $\begin{array}{c}499 \\
(21 \%)\end{array}$ & $\begin{array}{l}1032 \\
(20 \%)\end{array}$ \\
\hline 4 & 1415 (19\%) & $1076(19 \%)$ & $339(18 \%)$ & $\begin{array}{c}458 \\
(19 \%) \\
\end{array}$ & $957(19 \%)$ \\
\hline 5 & $1499(20 \%)$ & $1119(20 \%)$ & $380(20 \%)$ & $\begin{array}{c}501 \\
(21 \%) \\
\end{array}$ & $998(20 \%)$ \\
\hline \multicolumn{6}{|c|}{ Charlson comorbidity score } \\
\hline 0 & 4838 (65\%) & $3856(69 \%)$ & $982(52 \%)$ & $\begin{array}{c}1352 \\
(56 \%) \\
\end{array}$ & $\begin{array}{c}3486 \\
(69 \%) \\
\end{array}$ \\
\hline $1-2$ & $2059(28 \%)$ & $1415(25 \%)$ & $644(34 \%)$ & $\begin{array}{c}779 \\
(32 \%) \\
\end{array}$ & $\begin{array}{c}1280 \\
(25 \%) \\
\end{array}$ \\
\hline $3+$ & 564 (8\%) & 303 (5\%) & 261 (14\%) & $\begin{array}{c}285 \\
(12 \%)\end{array}$ & 279 (6\%) \\
\hline \multicolumn{6}{|c|}{ Geographic region $^{3}$} \\
\hline A & $458(6 \%)$ & $344(6 \%)$ & $114(6 \%)$ & $131(5 \%)$ & $327(6 \%)$ \\
\hline $\mathrm{B}$ & $654(9 \%)$ & $464(8 \%)$ & $190(10 \%)$ & $216(9 \%)$ & 438 (9\%) \\
\hline $\mathrm{C}$ & $398(5 \%)$ & $339(6 \%)$ & $59(3 \%)$ & $81(3 \%)$ & $317(6 \%)$ \\
\hline
\end{tabular}


Use of radiotherapy for bladder cancer

\begin{tabular}{|c|c|c|c|c|c|}
\hline $\mathrm{D}$ & $920(12 \%)$ & $738(13 \%)$ & $182(10 \%)$ & $\begin{array}{c}247 \\
(10 \%) \\
\end{array}$ & $673(13 \%)$ \\
\hline $\mathrm{E}$ & $315(4 \%)$ & $257(5 \%)$ & $58(3 \%)$ & $79(3 \%)$ & $236(5 \%)$ \\
\hline $\mathrm{F}$ & $468(6 \%)$ & $356(6 \%)$ & $112(6 \%)$ & $149(6 \%)$ & $319(6 \%)$ \\
\hline $\mathrm{G}$ & $569(8 \%)$ & $444(8 \%)$ & $125(7 \%)$ & $171(7 \%)$ & $398(8 \%)$ \\
\hline $\mathrm{H}$ & $720(10 \%)$ & $583(10 \%)$ & $137(7 \%)$ & $189(8 \%)$ & $531(11 \%)$ \\
\hline $\mathrm{I}$ & $819(11 \%)$ & $686(12 \%)$ & $133(7 \%)$ & $201(8 \%)$ & $618(12 \%)$ \\
\hline $\mathrm{J}$ & $394(5 \%)$ & $261(5 \%)$ & $133(7 \%)$ & $186(8 \%)$ & $208(4 \%)$ \\
\hline K & 832 (11\%) & $445(8 \%)$ & 387 (21\%) & $\begin{array}{c}433 \\
(18 \%)\end{array}$ & 399 (8\%) \\
\hline $\mathrm{L}$ & $273(4 \%)$ & $233(4 \%)$ & $40(2 \%)$ & $57(2 \%)$ & $216(4 \%)$ \\
\hline $\mathrm{M}$ & $507(7 \%)$ & $338(6 \%)$ & $169(9 \%)$ & $208(9 \%)$ & $299(6 \%)$ \\
\hline $\mathrm{N}$ & $130(2 \%)$ & $85(2 \%)$ & $45(2 \%)$ & $66(3 \%)$ & $64(1 \%)$ \\
\hline \multicolumn{6}{|l|}{ Rural $^{4}$} \\
\hline $\mathrm{N}$ & $6271(84 \%)$ & 4720 (85\%) & $1551(82 \%)$ & $\begin{array}{l}2006 \\
(83 \%)\end{array}$ & $\begin{array}{c}4265 \\
(85 \%)\end{array}$ \\
\hline Y & $1179(16 \%)$ & 848 (15\%) & $331(18 \%)$ & $\begin{array}{c}405 \\
(17 \%)\end{array}$ & $774(15 \%)$ \\
\hline \multicolumn{6}{|l|}{ Histology (OCR) $^{5}$} \\
\hline Adenocarcinoma & $222(3 \%)$ & $172(3 \%)$ & $50(3 \%)$ & $71(3 \%)$ & $151(3 \%)$ \\
\hline TCC non-papillary & $3814(51 \%)$ & $2901(52 \%)$ & $913(48 \%)$ & $\begin{array}{c}1213 \\
(50 \%) \\
\end{array}$ & $\begin{array}{c}2601 \\
(52 \%) \\
\end{array}$ \\
\hline TCC papillary & 3163 (42\%) & $2284(41 \%)$ & 879 (47\%) & $\begin{array}{c}1068 \\
(44 \%)\end{array}$ & $\begin{array}{c}2095 \\
(42 \%)\end{array}$ \\
\hline Squamous & $238(3 \%)$ & $193(3 \%)$ & $45(2 \%)$ & $64(3 \%)$ & $174(3 \%)$ \\
\hline \multicolumn{6}{|l|}{ Study period } \\
\hline 1994-1998 & 1415 (19\%) & 927 (17\%) & 488 (26\%) & $\begin{array}{c}574 \\
(24 \%) \\
\end{array}$ & $841(17 \%)$ \\
\hline 1999-2003 & $1640(22 \%)$ & $1231(22 \%)$ & 409 (22\%) & $\begin{array}{c}502 \\
(21 \%) \\
\end{array}$ & $\begin{array}{l}1138 \\
(23 \%) \\
\end{array}$ \\
\hline 2004-2008 & 2204 (30\%) & $1721(31 \%)$ & $483(26 \%)$ & $\begin{array}{c}622 \\
(26 \%) \\
\end{array}$ & $\begin{array}{c}1582 \\
(31 \%) \\
\end{array}$ \\
\hline 2009-2013 & $2202(30 \%)$ & 1695 (30\%) & 507 (27\%) & $\begin{array}{c}718 \\
(30 \%) \\
\end{array}$ & $\begin{array}{c}1484 \\
(29 \%) \\
\end{array}$ \\
\hline
\end{tabular}

Note: Percentages may not add to $100 \%$ due to rounding. ${ }^{1}$ Age is based on date of definitive treatment. Quintile 1 represents the communities where the poorest $20 \%$ of the Ontario population resided. Socioeconomic data were not available for 28 patients. ${ }^{3}$ Geographical region data were not available for less than six patients. ${ }^{4}$ Rurality data were not available for 11 patients. ${ }^{5}$ Histology data were not available for 24 patients. OCR: Ontario Cancer Registry; TCC: transitional cell carcinoma. 


\begin{tabular}{|c|c|c|c|}
\hline \multirow[t]{2}{*}{ Characteristic } & \multirow{2}{*}{ Proportion with RT } & \multicolumn{2}{|c|}{ Multivariate analyses } \\
\hline & & OR (95\% CI) & $\mathbf{p}$ \\
\hline Sex & & & 0.086 \\
\hline Male & $26 \%$ & Ref & \\
\hline Female & $24 \%$ & $0.89(0.77-1.02)$ & \\
\hline Age, years & & & $<0.001$ \\
\hline $20-49$ & $11 \%$ & Ref & \\
\hline $50-59$ & $13 \%$ & $1.33(0.85-2.08)$ & \\
\hline $60-69$ & $15 \%$ & $1.38(0.90-2.10)$ & \\
\hline $70-79$ & $23 \%$ & $2.40(1.59-3.62)$ & \\
\hline $80+$ & $50 \%$ & $9.34(6.16-14.1)$ & \\
\hline Socioeconomic status, quintile $^{1}$ & & 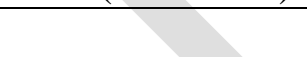 & 0.592 \\
\hline 1 & $27 \%$ & Ref & \\
\hline 2 & $24 \%$ & $0.89(0.74-1.06)$ & \\
\hline 3 & $26 \%$ & $0.94(0.78-1.12)$ & \\
\hline 4 & $24 \%$ & $0.90(0.75-1.09)$ & \\
\hline 5 & $25 \%$ & $0.87(0.72-1.05)$ & \\
\hline Charlson comorbidity & 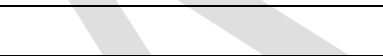 & & $<0.001$ \\
\hline 0 & $20 \%$ & Ref & \\
\hline $1-2$ & $31 \%$ & $1.63(1.43-1.85)$ & \\
\hline $3+$ & $46 \%$ & $3.17(2.60-3.88)$ & \\
\hline Geographic region & 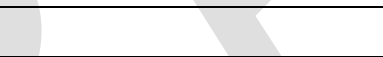 & & $<0.001$ \\
\hline $\mathrm{A}$ & $25 \%$ & $1.91(1.41-2.59)$ & \\
\hline 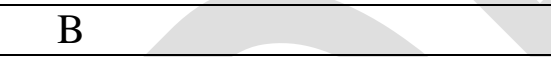 & $29 \%$ & $2.09(1.59-2.76)$ & \\
\hline 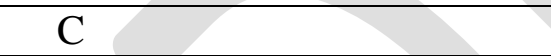 & $15 \%$ & $0.97(0.68-1.38)$ & \\
\hline $\mathrm{D}$ & $20 \%$ & $1.31(1.00-1.71)$ & \\
\hline $\mathrm{E}$ & $18 \%$ & 1.37 (0.95-1.97) & \\
\hline F & $24 \%$ & $1.81(1.33-2.47)$ & \\
\hline $\mathrm{G}$ & $22 \%$ & $1.39(1.03-1.86)$ & \\
\hline 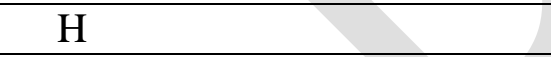 & $19 \%$ & $1.28(0.96-1.69)$ & \\
\hline+2 & $16 \%$ & Ref & \\
\hline+2 & $34 \%$ & $3.22(2.37-4.38)$ & \\
\hline $\mathrm{K}$ & $47 \%$ & $5.55(4.32-7.14)$ & \\
\hline $\mathrm{L}$ & $15 \%$ & $1.04(0.69-1.56)$ & \\
\hline $\mathrm{M}$ & $33 \%$ & $2.89(2.17-3.85)$ & \\
\hline $\mathrm{N}$ & $35 \%$ & $2.87(1.83-4.52)$ & \\
\hline Rural & & & 0.937 \\
\hline No & $25 \%$ & Ref & \\
\hline Yes & $28 \%$ & $0.99(0.84-1.17)$ & \\
\hline Histology (OCR) & & & 0.100 \\
\hline
\end{tabular}




\begin{tabular}{|c|c|c|c|}
\hline Adenocarcinoma & $23 \%$ & $1.08(0.75-1.56)$ & \\
\hline TCC non-papillary & $24 \%$ & Ref & \\
\hline TCC papillary & $28 \%$ & $1.11(0.98-1.25)$ & \\
\hline Squamous & $19 \%$ & $0.74(0.51-1.07)$ & \\
\hline Study period & & & $<0.001$ \\
\hline $1994-1998$ & $34 \%$ & $2.20(1.86-2.60)$ & \\
\hline $1999-2003$ & $25 \%$ & $1.23(1.05-1.46)$ & \\
\hline $2004-2008$ & $22 \%$ & $0.93(0.79-1.09)$ & \\
\hline $2009-2013$ & $23 \%$ & Ref & \\
\hline
\end{tabular}

${ }^{1}$ Quintile 1 represents the communities where the poorest $20 \%$ of the Ontario population resided. CI: confidence interval; OCR: Ontario Cancer Registry; OR: odds ratio; TCC: transitional cell carcinoma. 


\begin{tabular}{|c|c|c|c|c|c|c|}
\hline \multirow[t]{3}{*}{ Characteristic } & \multicolumn{3}{|c|}{$\begin{array}{l}\text { Factors associated with seeing } \mathrm{RO} \text { before radical } \\
\text { treatment }(\mathrm{n}=7461)\end{array}$} & \multicolumn{3}{|c|}{$\begin{array}{c}\text { Factors associated with receiving } \mathrm{RT} \text { among } \\
\text { cases seen by RO (n=2416) }\end{array}$} \\
\hline & \multirow{2}{*}{$\begin{array}{c}\begin{array}{c}\text { Proportion } \\
\text { seen by RO }\end{array} \\
n=2416 \\
\end{array}$} & \multicolumn{2}{|c|}{ Multivariate analyses } & \multirow{2}{*}{$\begin{array}{c}\begin{array}{c}\text { Proportion } \\
\text { with RT }\end{array} \\
\mathbf{n}=1813\end{array}$} & \multicolumn{2}{|c|}{ Multivariate analyses } \\
\hline & & OR (95\% CI) & $\mathbf{p}$ & & OR (95\% CI) & $\mathbf{p}$ \\
\hline \multicolumn{7}{|l|}{ Patient-level } \\
\hline Sex & & & 0.434 & & & 0.063 \\
\hline Male & $33 \%$ & Ref & 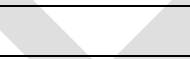 & $76 \%$ & Ref & \\
\hline Female & $32 \%$ & $0.95(0.84-1.08)$ & 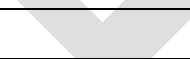 & $73 \%$ & $0.78(0.61-1.01)$ & \\
\hline Age, years & & 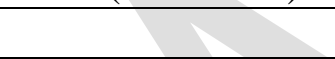 & $<0.001$ & & & $<0.001$ \\
\hline $20-49$ & $20 \%$ & Ref & +2 & $48 \%$ & Ref & \\
\hline $50-59$ & $21 \%$ & $0.97(0.69-1.37)$ & 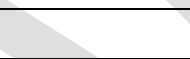 & $59 \%$ & $1.56(0.74-3.30)$ & \\
\hline $60-69$ & $23 \%$ & $1.01(0.73-1.39)$ & 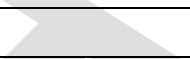 & $64 \%$ & $2.11(1.04-4.28)$ & \\
\hline $70-79$ & $31 \%$ & $1.51(1.10-2.06)$ & & $74 \%$ & $3.26(1.64-6.48)$ & \\
\hline $80+$ & $56 \%$ & 4.59 (3.33-6.32) & & $87 \%$ & $10.42(5.15-21.07)$ & \\
\hline $\begin{array}{l}\text { Socioeconomic status, } \\
\text { quintile }^{1}\end{array}$ & & & 0.845 & & & 0.068 \\
\hline 1 & $32 \%$ & Ref & 2 & $79 \%$ & Ref & \\
\hline 2 & $31 \%$ & $0.97(0.82-1.15)$ & 2 & $75 \%$ & $1.48(1.02-2.13)$ & \\
\hline 3 & $33 \%$ & $1.02(0.86-1.20)$ & & $77 \%$ & $1.29(0.91-1.84)$ & \\
\hline 4 & $32 \%$ & $1.07(0.90-1.27)$ & & $69 \%$ & $1.22(0.85-1.74)$ & \\
\hline 5 & $33 \%$ & $1.04(0.88-1.23)$ & & $74 \%$ & $0.92(0.65-1.30)$ & \\
\hline Charlson comorbidity & $\mathbf{s}$ & & $<0.001$ & & & $<0.001$ \\
\hline 0 & $28 \%$ & Ref & & $70 \%$ & Ref & \\
\hline $1-2$ & $38 \%$ & $1.44(1.28-1.62)$ & & $79 \%$ & $1.46(1.14-1.88)$ & \\
\hline $3+$ & $51 \%$ & $2.43(2.00-2.94)$ & & $88 \%$ & $3.26(2.10-5.06)$ & \\
\hline Geographic region & & & $<0.001$ & & & 0.013 \\
\hline A & $29 \%$ & $1.28(0.98-1.69)$ & & $84 \%$ & $2.04(1.00-4.17)$ & \\
\hline
\end{tabular}


Wei et al

Use of radiotherapy for bladder cancer

\begin{tabular}{|c|c|c|c|c|c|c|}
\hline $\mathrm{B}$ & $33 \%$ & $1.47(1.16-1.88)$ & & $82 \%$ & $2.03(1.09-3.80)$ & \\
\hline $\mathrm{C}$ & $20 \%$ & $0.81(0.60-1.10)$ & & $73 \%$ & $1.62(0.79-3.32)$ & \\
\hline $\mathrm{D}$ & $27 \%$ & $1.12(0.89-1.41)$ & & $72 \%$ & $1.25(0.70-2.25)$ & \\
\hline $\mathrm{E}$ & $25 \%$ & $1.12(0.82-1.54)$ & & $70 \%$ & $0.97(0.49-1.93)$ & \\
\hline $\mathrm{F}$ & $32 \%$ & $1.47(1.12-1.92)$ & & $70 \%$ & $1.17(0.65-2.09)$ & \\
\hline G & $30 \%$ & $1.26(0.97-1.62)$ & & $71 \%$ & $1.27(0.71-2.26)$ & \\
\hline $\mathrm{H}$ & $26 \%$ & $1.08(0.85-1.38)$ & & $70 \%$ & $1.01(0.59-1.72)$ & \\
\hline $\mathrm{I}$ & $25 \%$ & Ref & 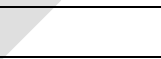 & $64 \%$ & Ref & \\
\hline $\mathrm{J}$ & $47 \%$ & $3.30(2.51-4.33)$ & & $68 \%$ & $1.05(0.59-1.87)$ & \\
\hline $\mathrm{K}$ & $52 \%$ & $3.72(2.98-4.65)$ & & $85 \%$ & $2.80(1.55-5.06)$ & \\
\hline $\mathrm{L}$ & $21 \%$ & $0.90(0.63-1.29)$ & & $68 \%$ & $1.03(0.47-2.28)$ & \\
\hline $\mathrm{M}$ & $41 \%$ & $2.31(1.79-2.98)$ & 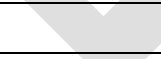 & $80 \%$ & $2.07(1.13-3.79)$ & \\
\hline $\mathrm{N}$ & $51 \%$ & $3.40(2.26-5.11)$ & 8 & $65 \%$ & $0.94(0.37-2.37)$ & \\
\hline Rural & & - & 0.290 & & & 0.365 \\
\hline No & $32 \%$ & Ref & 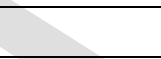 & $74 \%$ & Ref & \\
\hline Yes & $34 \%$ & $0.92(0.79-1.07)$ & 2 & $78 \%$ & $1.17(0.84-1.63)$ & \\
\hline Histology (OCR) & & 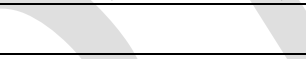 & 0.325 & & & 0.033 \\
\hline Adenocarcinoma & $32 \%$ & $1.17(0.85-1.60)$ & & $66 \%$ & $0.99(0.51-1.92)$ & \\
\hline TCC non-papillary & $32 \%$ & Ref & & $73 \%$ & Ref & \\
\hline TCC papillary & $34 \%$ & $1.01(0.91-1.13)$ & & $79 \%$ & $1.42(1.12-1.80)$ & \\
\hline Squamous & $27 \%$ & $0.78(0.57-1.07)$ & $\mathrm{S}$ & $67 \%$ & $1.06(0.55-2.06)$ & \\
\hline Study period & & +2 & $<0.001$ & & & $<0.001$ \\
\hline 1994-1998 & $41 \%$ & $1.61(1.39-1.88)$ & & $82 \%$ & $3.80(2.56-5.63)$ & \\
\hline 1999-2003 & $31 \%$ & $0.95(0.82-1.10)$ & & $78 \%$ & $2.20(1.55-3.12)$ & \\
\hline 2004-2008 & $28 \%$ & $0.80(0.69-0.92)$ & & $75 \%$ & $1.56(1.15-2.10)$ & \\
\hline 2009-2013 & $33 \%$ & Ref & & $68 \%$ & Ref & $<0.001$ \\
\hline \multicolumn{7}{|l|}{ Referring physician } \\
\hline Urology & & - & & $75 \%$ & Ref & \\
\hline Medical oncology & & - & & $87 \%$ & $2.76(1.88-4.06)$ & \\
\hline Radiation oncology & & - & & $81 \%$ & $1.17(0.28-4.85)$ & \\
\hline Primary care & & - & & $67 \%$ & $0.53(0.35-0.83)$ & \\
\hline
\end{tabular}


Wei et al

Use of radiotherapy for bladder cancer

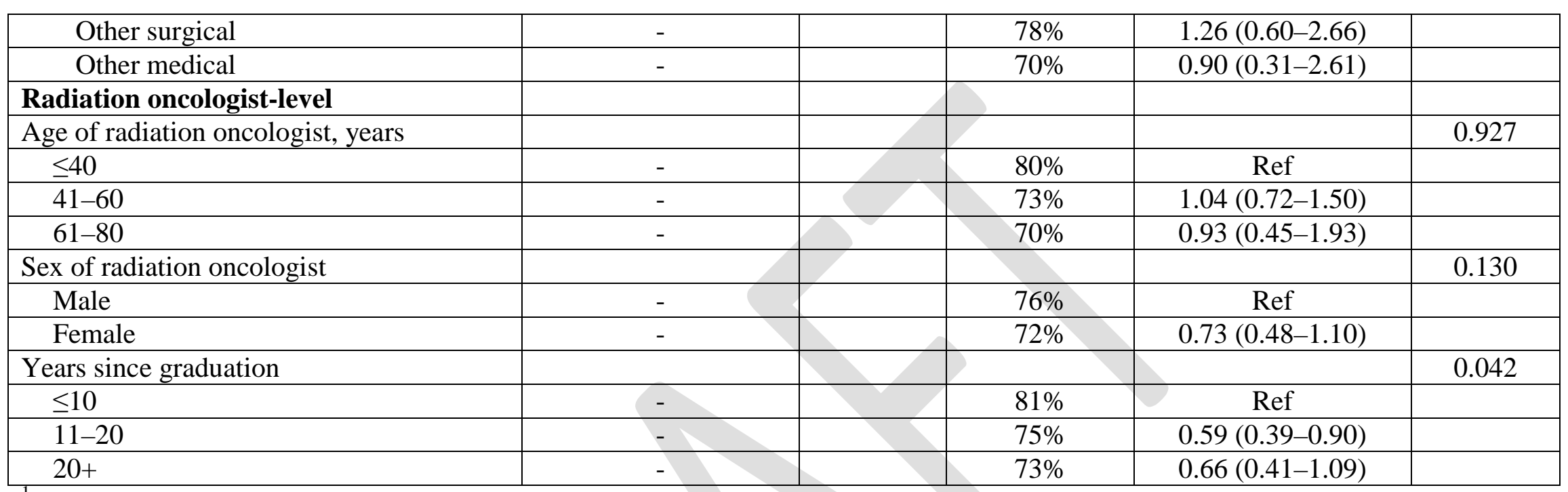

${ }^{1}$ Quintile 1 represents the communities where the poorest $20 \%$ of the Ontario population resided. CI: confidence interval; OCR:

Ontario Cancer Registry; OR, odds ratio; TCC: transitional cell carcinoma. 


\begin{tabular}{|c|c|c|c|}
\hline \multirow[t]{3}{*}{ Characteristic } & \multirow{3}{*}{$\begin{array}{c}\begin{array}{c}\text { Proportion seen } \\
\text { by RO }\end{array} \\
\mathbf{n}=603 \\
\end{array}$} & \multicolumn{2}{|c|}{$\begin{array}{c}\text { Factors associated with seeing RO before } \\
\text { cystectomy }\end{array}$} \\
\hline & & & \\
\hline & & OR (95\% CI) & $\mathbf{p}$ \\
\hline Patient-level & & 0 & \\
\hline Sex & & 2 & 0.883 \\
\hline Male & $11 \%$ & Ref & \\
\hline Female & $11 \%$ & $1.02(0.81-1.27)$ & \\
\hline Age, years & & (es & 0.003 \\
\hline $20-49$ & $12 \%$ & Ref & \\
\hline $50-59$ & $10 \%$ & $0.92(0.54-1.56)$ & \\
\hline $60-69$ & $10 \%$ & $0.83(0.50-1.36)$ & \\
\hline $70-79$ & $11 \%$ & $1.03(0.63-1.68)$ & \\
\hline $80+$ & $14 \%$ & $1.52(0.90-2.56)$ & \\
\hline Socioeconomic status, quintile $^{1}$ & (a) & - & 0.289 \\
\hline 1 & $9 \%$ & 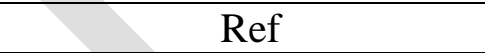 & \\
\hline 2 & $10 \%$ & $0.92(0.66-1.27)$ & \\
\hline 3 & $10 \%$ & $1.01(0.74-1.36)$ & \\
\hline 4 & $13 \%$ & $1.04(0.77-1.40)$ & \\
\hline 5 & $12 \%$ & $1.27(0.95-1.70)$ & \\
\hline Charlson comorbidity & & & 0.910 \\
\hline 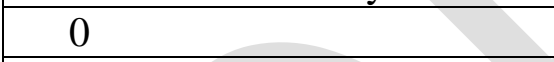 & $11 \%$ & Ref & \\
\hline $1-2$ & $11 \%$ & $1.01(0.81-1.26)$ & \\
\hline 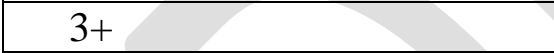 & $11 \%$ & $0.91(0.59-1.41)$ & \\
\hline \begin{tabular}{|l|} 
Geographic region \\
\end{tabular} & 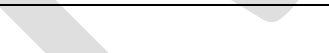 & & 0.040 \\
\hline$+\frac{1}{2}$ & $6 \%$ & $0.55(0.28-1.10)$ & \\
\hline 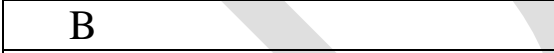 & $8 \%$ & $0.64(0.35-1.20)$ & \\
\hline 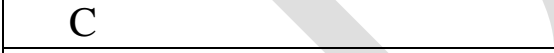 & $6 \%$ & $0.57(0.30-1.11)$ & \\
\hline 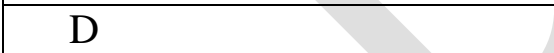 & $9 \%$ & $0.55(0.33-0.94)$ & \\
\hline+2 & $9 \%$ & $1.01(0.55-1.84)$ & \\
\hline 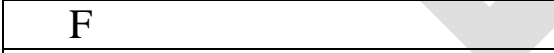 & $12 \%$ & $1.00(0.60-1.65)$ & \\
\hline 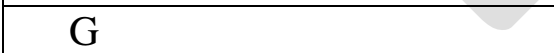 & $11 \%$ & $0.62(0.39-1.00)$ & \\
\hline $\mathrm{H}$ & $10 \%$ & $0.74(0.48-1.16)$ & \\
\hline I & $10 \%$ & Ref & \\
\hline $\mathrm{J}$ & $23 \%$ & $1.06(0.54-2.08)$ & \\
\hline $\mathrm{K}$ & $14 \%$ & $0.89(0.48-1.63)$ & \\
\hline $\mathrm{L}$ & $8 \%$ & $0.62(0.31-1.21)$ & \\
\hline $\mathrm{M}$ & $12 \%$ & $0.78(0.45-1.38)$ & \\
\hline $\mathrm{N}$ & $27 \%$ & $2.75(1.17-6.44)$ & \\
\hline
\end{tabular}




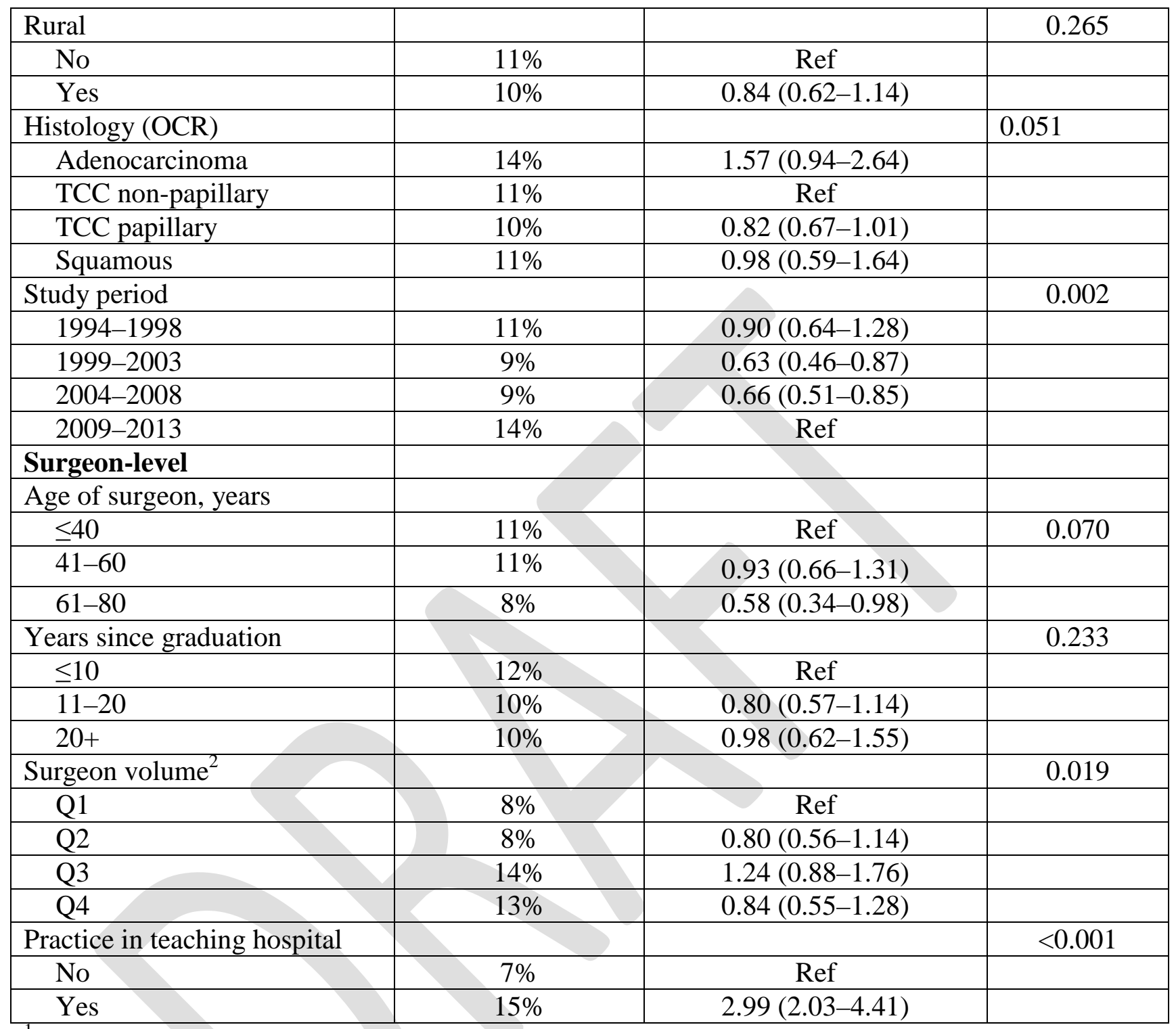

${ }^{1}$ Quintile 1 represents the communities where the poorest $20 \%$ of the Ontario population resided.

${ }^{2}$ Quartile 1 represents the lowest surgeon volumes. CI: confidence interval; OCR: Ontario Cancer Registry; OR: odds ratio; TCC: transitional cell carcinoma. 
Supplementary Fig. 1. Identification of patients with muscle-invasive bladder cancer with cystectomy in Ontario, 1994-2013.

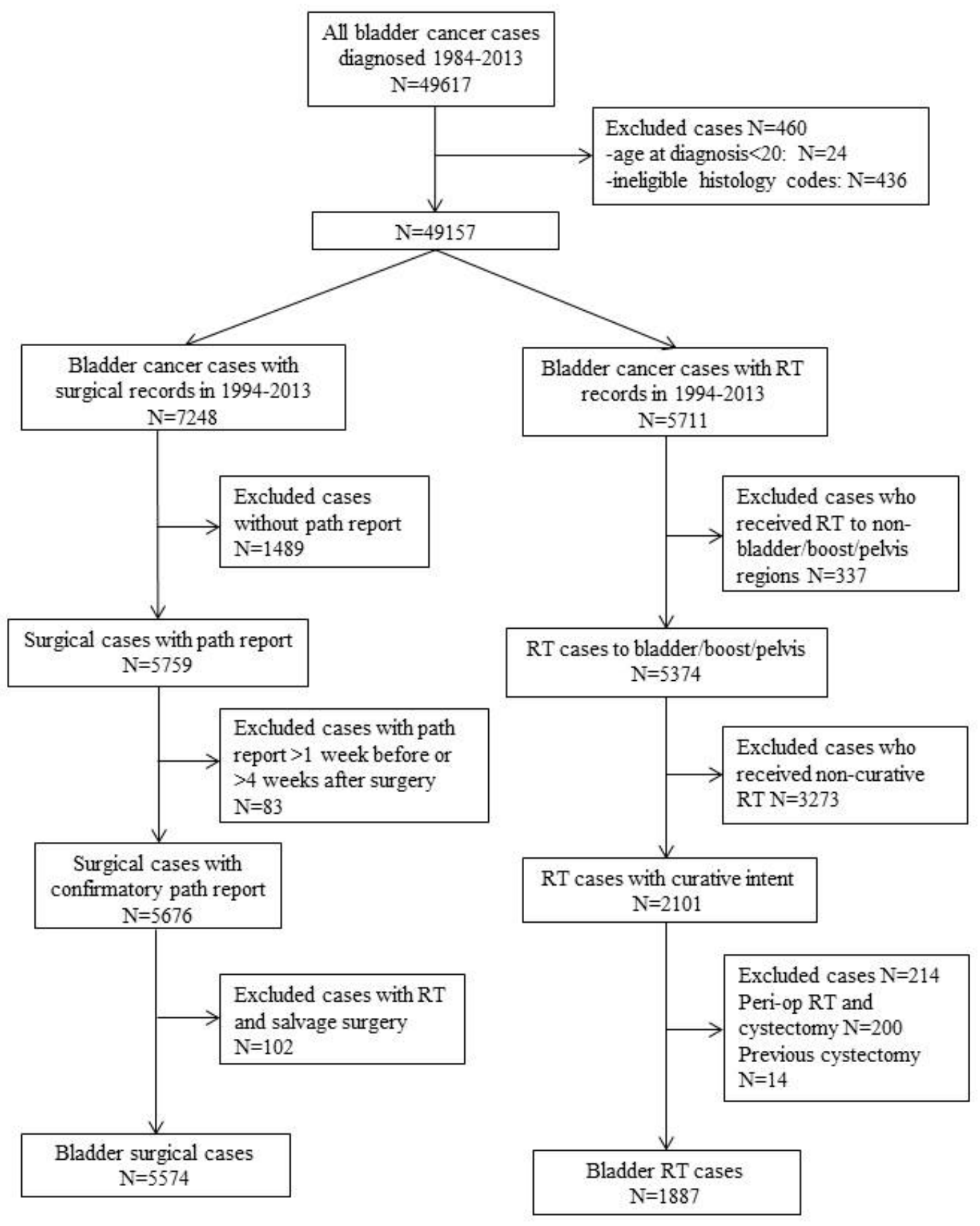


Supplementary Fig. 2. Referring physician for radiation oncology consultation in patients who were seen by radiation oncology before radical treatment in Ontario, 1994-2013.

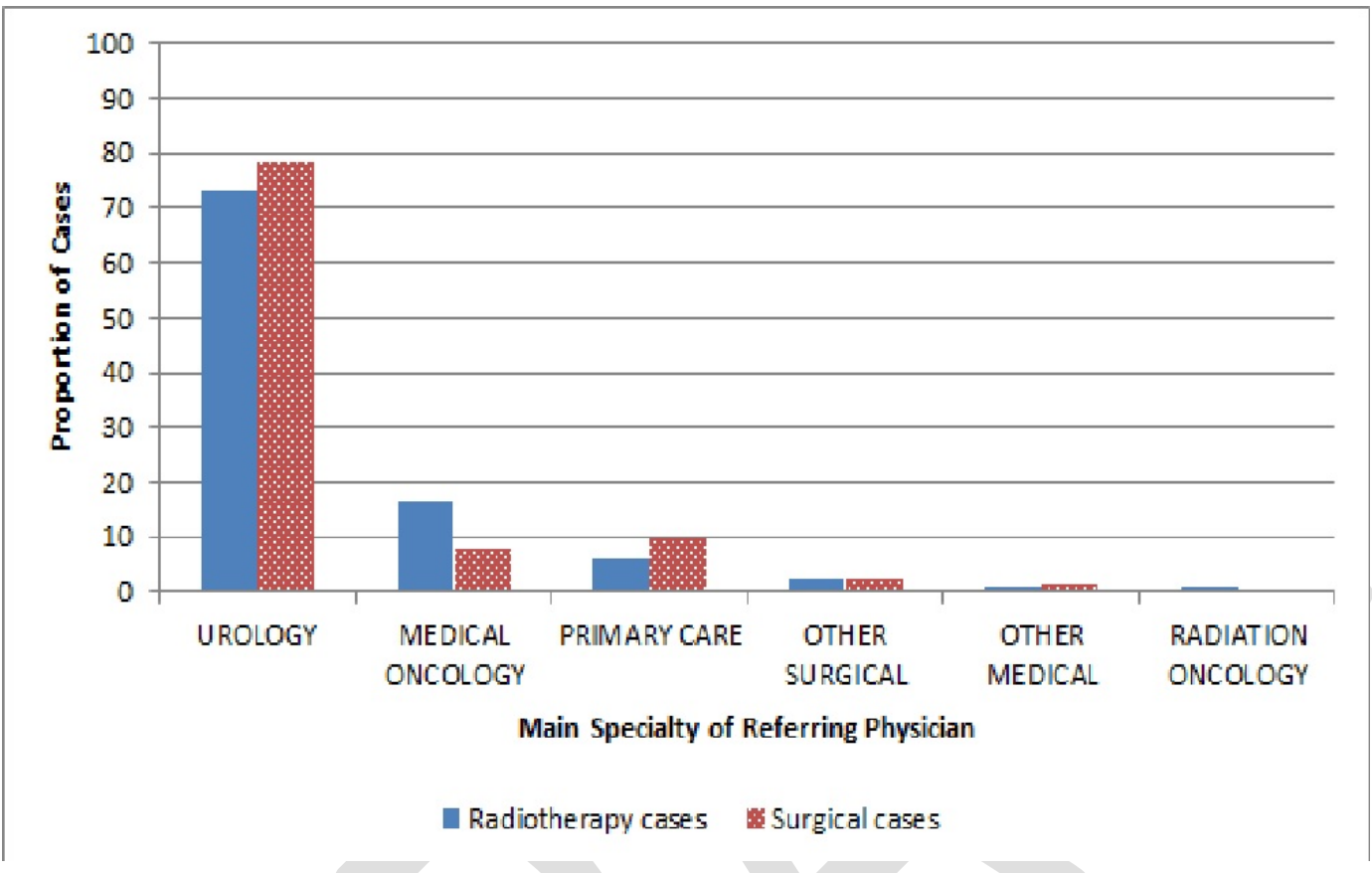

